\title{
Simulations of Southern Hemisphere warming and Antarctic sea-ice changes using global climate models
}

\author{
Xingren Wu, W. F. Budd, ${ }^{2}$ T. H. JaGKA ${ }^{1}$ \\ ${ }^{1}$ Antarctic CRC and Australian Antarctic Division, Box 252-80, Hobart, Tasmania 7001, Australia \\ ${ }^{2}$ Antarctic CRC, Box 252-80, Hobart, Tasmania 7001, Australia
}

\begin{abstract}
A combination of modelling techniques is used in conjunction with the limited available observational data to examine Antarctic sea-ice changes with global warming over the past century. Firstly, a coupled global climate model is forced by prescribing the effect of increasing greenhouse gases from last century to the present. Secondly, the GISST (U.K. Meteorological Office global sea-ice and sea surface temperature) observational dataset is used to force an atmosphere-sea-ice model to compute changes in the Antarctic sea ice from last century to the present. Thirdly, the global sea-surface-temperature (SST) anomalies derived from the coupled model are used to force the atmosphere-sea-ice model over the same period. The change in the Southern Hemisphere annual mean surface temperature simulated by the coupled model with greenhouse-gas forcing is about $0.6^{\circ} \mathrm{C}$, which is similar to the observed change. Over the Antarctic (poleward of $60^{\circ} \mathrm{S}$ ) the corresponding simulated change is about $0.7^{\circ} \mathrm{C}$, which also appears compatible with observations. The reduction in summer sea-ice extent simulated by the CSIRO Commonwealth Scientific and Industrial Research Organisation) coupled model is $0.44^{\circ}$ lat. which is, in general, less than the observed change. For the two SST forcing cases the changes are, in general, larger than indicated by the observations. It is concluded that future changes of reduced sea-ice extent from increasing greenhouse gases as simulated by the CSIRO coupled model are not expected to be overestimates.
\end{abstract}

\section{INTRODUGTION}

Observations have shown that a small but significant Antarctic warming has occurred over the past century (Jacka and Budd, 1998), and the average Antarctic sea-ice extent may have reduced by about $5 \times 10^{6} \mathrm{~km}^{2}$ (over $2^{\circ}$ lat.) from the early 1930s to the mid-1970s (De la Mare, 1997). It is known that the Antarctic sea ice plays a pivotal role in global climate (e.g. Budd, 1991; Hanna, 1996). Interaction of sea ice with the atmosphere above and the ocean beneath influences the polar climate. The change of the ice cover influences the turbulent- (sensible- and latent-) heat transfer, the absorption of solar radiation at the surface, the formation of cloud, wind stress, ocean currents, oceanic heat flux, salinity, bottom water formation and other factors, and through feedbacks affects the climate at lower latitudes. The changed climate can in turn influence the sea-ice distribution which is a sensitive indicator of climatic change (Baker, 1986). It is therefore important to be able to simulate an accurate representation of the sea-ice distribution and its past changes with time in coupled global climate models to provide confidence in the use of the models for future climate-change studies. In this work we use a combination of modelling techniques in conjunction with the limited available observational data to examine Antarctic sea-ice changes with global warming over the past century.

\section{DESGRIPTION OF MODELS}

The CSIRO (Commonwealth Scientific and Industrial
Research Organisation) global climate model (GCM) (Gordon and O'Farrell, 1997) is a comprehensive GCM comprising sub-models of the atmosphere, ocean, sea ice and land biosphere. The atmospheric model is spectral, with 21 wave (R21) and 9 (sigma) vertical levels (McGregor and others, 1993). The ocean model is the standard GFDL (Geophysical Fluid Dynamics Laboratory) model but includes oceanic eddy-induced advection (Hirst and McDougall, 1996), according to the Gent and McWilliams (1990) scheme which improves the model simulation (Hirst and others, 1996). The seaice model (Gordon and O'Farrell, 1997; O'Farrell, 1998) includes the three-layer thermodynamic treatment of Semtner (1976), with ice dynamics based on Flato and Hibler (1992).

The Melbourne University atmosphere-sea-ice model includes a 21 wave (R21) 9 (sigma) level atmospheric general circulation model (Simmonds, 1985) and a dynamicthermodynamic sea-ice model (Wu and others, 1997). The thermodynamic representation of the sea-ice model is the Semtner (1976) "zero-layer" version model plus a parameterisation for leads and albedo of ice and snow given by Wu and others (1997). The dynamics of the sea-ice model is similar to but simpler than the "cavitating-fluid" version of the Flato and Hibler model (1992), with only the compressive stresses effective in the sea ice. At low ice concentration the sea ice is modelled to move in free drift, with a speed taken to be $2 \%$ of the (instantaneous) atmospheric wind, and at an angle of $25^{\circ}$ to the left of it (in the Southern Hemisphere). Internal resistance of sea ice to deformation occurs at high concentrations of sea ice, and a mass conservative parameterisation of the rafting processes, which is ice-thickness and open-water- 
fraction dependent, is included (Worby and Wu, 1998; Wu and others, 1999).

\section{EXPERIMENTS AND DATA}

In this study we examine changes in the Antarctic sea ice which have occurred along with changes in surface temperature over the past century, by using a combination of modelling techniques in comparison with the limited observational data available. Firstly, we use the CSIRO coupled GCM forced by the increasing greenhouse gases from last century (starting in AD 1880) to the present and on into the future. The equivalent $\mathrm{CO}_{2}$ used is varied to give the same radiative forcing change as resulting from the total greenhouse-gas build-up observed for the calendar years 1880-1990 and estimated according to the IS92a scenario for 1991-2082 (Houghton and others, 1996). The equivalent $\mathrm{CO}_{2}$ reaches three times the 1880 value at 2082 and is held constant thereafter (Hirst, 1999). It should be noted that the IS92a scenario is about in the middle of the IS92 "family". In this work we focus on the simulation over the Southern Hemisphere from 1880 to the present and to the end of next century. Secondly, in order to examine how the sea-ice changes relate directly to the temperature changes alone, we use the Melbourne University atmosphere-sea-ice model forced with the Reynolds (1988) sea-surface-temperature (SST) climatology and the GISST (U.K. Meteorological Office global sea-ice and SST; Parker and others, 1995a) anomalies of 1881-1910 from 1980-94 to compute changes in the Antarctic sea ice from last century to the present. Thirdly, we use the Melbourne University atmosphere-sea-ice model forced with Reynolds (1988) SST climatology and the global SSTanomalies derived from the CSIRO coupled-model simulation, to model the changes in the Antarctic sea ice. In this way we assess the relation between the sea-ice and SST changes and examine how both change with the greenhouse-gas forcing in comparison with observations.

Reasonably accurate observations of the sea-ice distribution have been available from satellites since the early 1970s. Some limited sea-ice data are available over a longer timescale from a variety of sources which include observations made from ships and aircraft, and from coastal and island stations, and indirect observations derived from whaling records (De la Mare, 1997). However, the Antarctic sea-ice distribution was not well known prior to the 1960s (Parkinson, 1990). The observational data of sea ice used in this study comprise a number of compilations based on ship observations, including the early data from last century which were published by Parkinson (1990), in conjunction with the most recent satellite observations of the Special Sensor Microwave Imager (SSM/I) (1988-95). The observed sea-ice extent for the historical data used is the combination of results of the expeditions of Cook, Bellingshausen and Wilkes in the late 18th and early 19th centuries (see Parkinson, 1990, for details). The sea-ice extent observed by Cook, Bellingshausen and Wilkes may differ from that of the later period, 1881-1910. However, the more comprehensive compilations of sea-ice extent made from the later ship observations, including the Belgica, Deutchland, Gauss and Endurance (Meinardus, 1938) and the Discovery (Herdman, 1948), provide further evidence that there was little long-term net change in the sea-ice extent through the 19th century when compared to the large interannual variability (Renkin, 1997). Therefore in this study we use the sea-ice extent observed by Cook, Bellingshausen and
Wilkes relative to the extent of ice at the same locations at the same time of year from the most recent satellite data to represent the sea-ice extent of 1881-1910, although this may only provide a limited indicative estimate of the sea-ice-extent reduction over the past century. The temperature data are taken from the combined land-air and sea-surface temperature of Jones (1994), Parker and others (1995b) and Kelly and Jones (1996). The observations over the Antarctic are from Jacka (unpublished data, http://www.antcrc.utas.edu. $\mathrm{au} / \sim$ jacka/climate. html).

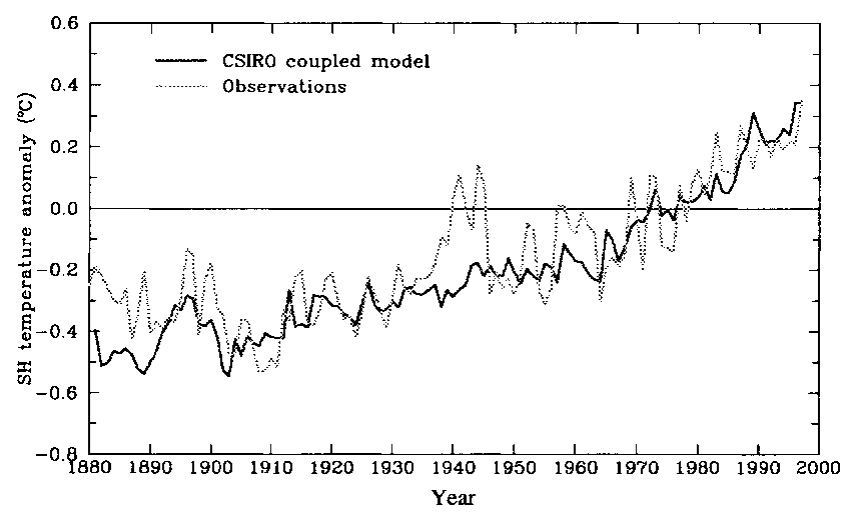

Fig. 1. Southern Hemisphere annual mean surface-temperature anomalies, 1881-1997 (relative to the long-term mean, 196190), as simulated by the CSIRO coupled model and compiled from observations (Jones, 1994; Parker and others, 1995b).

\section{RESULTS}

\subsection{Temperature}

Southern Hemisphere surface-temperature anomalies (relative to 1961-90) simulated by the CSIRO coupled model are compared with observations in Figure 1. The observational data are the combined land-air and sea-surface temperatures from the global dataset (Jones, 1994; Parker and others, 1995b) also computed as anomalies from the 1961-90 average. It is recognised that observations in the higher latitudes for the early periods are very sparse, but the close agreement between the model results and observations also holds well over all latitudes, including the domain of lower latitudes where the observations are more robust.

Table 1. Averages of surface temperature changes $\left({ }^{\circ} C\right)$ from 1881-1910 and 1950-64 to 1980-94 for the globe (G), the Southern Hemisphere (SH), the region 25-65 $S$ (SOC) and the Antarctic $\left(60^{\circ} \mathrm{S}\right.$ poleward), from observations (Kelly and Fones, 1996) and model simulations

Temperature change from 1881-1910 to 1980-94

$G \quad S H \quad S O C \quad$ Antarctic

\begin{tabular}{lclcc} 
Observations & 0.53 & 0.52 & 0.59 & - \\
CSIRO coupled model & 0.70 & 0.58 & 0.53 & 0.70 \\
& \multicolumn{5}{c}{ Temperature change from } & 1950-64 & to & 1980-94 \\
& 0.23 & 0.32 & 0.34 & 0.41 \\
Observations & 0.45 & 0.35 & 0.29 & 0.43 \\
CSIRO coupled model & & &
\end{tabular}


Regional average surface mean-temperature changes from 1881-1910 to 1980-94 and 1950-64 to 1980-94 are compared in Table 1. These include the globe, the Southern Hemisphere, the Southern Ocean sector (we choose the region $\left.25-65^{\circ} \mathrm{S}\right)$ and the Antarctic $\left(60^{\circ} \mathrm{S}\right.$ poleward). Because of the lack of observations over the Antarctic before the International Geophysical Year (1957-58), it is not practical for us to make comparisons between the model simulation and the observations on the time-scale of 100 years. It can be seen that the simulated surface-temperature changes compare well with the observed changes over both the past 100 years or so and the past 30 years. The simulated excessive global mean warming is due to the higher warming simulated in the Northern Hemisphere, possibly due to the lack of the cooling effect of aerosols not included in the model (Hirst, 1999).

Although the large-scale and long-term temperature changes are well simulated, the year-to-year variations of temperature can be quite large at any one location, and the model simulations can be quite different from observations. For example, Connolley and O'Farrell (1998) showed that the CSIRO coupled model (and two other models), when forced with atmospheric greenhouse gases, does not reproduce temperature changes as observed in the Antarctic Peninsula region over the past 50 years. The surface air-temperature increase simulated in the CSIRO coupled model at the South Orkney Islands (on Laurie Island, $60^{\circ} 45^{\prime} \mathrm{S}$, $44^{\circ} 43^{\prime} \mathrm{W}$ ) is also found to be less than that from the observations (Jacka, unpublished data). It can be seen in Figure 1 that the observed Southern Hemisphere warming during the 1940 s is not captured by the model simulation. In addition, the model greatly underestimates the interannual and multi-annual variability. There could be many reasons for this. Firstly, there are many processes in the real world which have not been included in the coupled model (e.g. the effect of volcanoes, aerosols and land-surface anthropogenetic and biofeedback effects). Secondly, the incomplete coverage of the observations and the changes in this coverage over time need to be kept in mind. Thirdly, the equivalent $\mathrm{CO}_{2}$ record used in the model was smoothed, and the initial magnitude and phase for any anomalies in the climate system, compared to those in the start of the coupled model, are unknown. Finally, there is a conservative influence of the flux correction used in the coupled model. Nevertheless, the model reasonably simulates the large-scale, long-term mean global warming over the past 100 years or so, and provides useful information for many other climatic variables which form part of the interactive climate system and for which there are either limited or no observations.

Table 2. Change in observed and simulated mean sea-ice extent. Units are ${ }^{\circ}$ lat.

\begin{tabular}{lrrrl}
\hline & OBS & CM & FCM & FGISST \\
\hline Cook & 1.17 & 0.65 & 1.43 & 2.03 \\
Bellingshausen & 1.03 & 0.46 & 0.84 & 1.29 \\
Wilkes & -0.05 & 0.25 & 0.62 & 0.8 \\
& & & & \\
\hline
\end{tabular}

Notes: The observed changes are estimated based on the observations of Cook, Bellingshausen and Wilkes and SSM/I observations, 1988-95. The simulated changes refer to the period 1881-1910 to 1980-94 and correspond to the same locations as the historical observations. Positive values mean sea ice moves to higher latitude, i.e. a reduction in sea-ice extent.
Table 3. Change in observed and simulated mean sea-ice extent, December-February. Units are ${ }^{\circ}$ lat.

\begin{tabular}{lcccc}
\hline & $\begin{array}{c}\text { OBS } \\
\text { (combined) }\end{array}$ & $C M$ & FCM & FGISST \\
\hline December & 1.10 & 0.41 & 1.30 & 1.91 \\
January & 0.24 & 0.29 & 0.57 & 1.02 \\
February & 0.36 & 1.04 & 0.99 & 1.07 \\
Mean & 0.71 & 0.44 & 0.91 & 1.31 \\
\hline
\end{tabular}

Notes: The observed changes are estimated based on the observations of Cook, Bellingshausen and Wilkes and SSM/I observations, 1988-95. The simulated changes refer to the period 1881-1910 to 1980-94 and correspond to the same locations as the historical observations. Positive values mean sea ice moves to higher latitude, i.e. a reduction in sea-ice extent.

\subsection{Sea-ice extent}

The change in latitude of observed sea-ice extent at each location (longitude) was calculated where available historical data permitted, and the mean changes are given in Table 2. The simulated mean changes from 1881-1910 to 1980-94 are also given in Table 2 for the CSIRO coupled model $(\mathrm{CM})$, and the Melbourne University atmosphere-sea-ice model forced with SST anomalies from the GISST data (FGISST) and from the CSIRO coupled-model-derived SST anomalies (FCM). To avoid any undue influence of extreme outliers when the change is $>4^{\circ}$ from the observations at any location, that location is excluded from the calculation of the averaged change. Comparing the ice-edge locations recorded by Cook (1777, as referred to in Parkinson, 1990) with those of the present (satellite observations of SSM/I, 1988-95) the sea ice reduces by about $1.17^{\circ}$, which is more than the CSIRO coupled-model simulation of $0.65^{\circ}$ for $1881-1910$ to 1980-94, but less than the SST forcing simulations which are $2.03^{\circ}$ for FGISST and $1.43^{\circ}$ for FCM. Comparing the ice-edge locations recorded by Bellingshausen (1831, as referred to in Parkinson, 1990) with those of the present, the sea ice reduces by about $1.03^{\circ}$, which is more than the simulations of CM $\left(0.46^{\circ}\right)$ and FCM $\left(0.84^{\circ}\right)$ but less than the simulation of FGISST $\left(1.29^{\circ}\right)$. In contrast to Cook's and Bellingshausen's observations, the ice-edge locations recorded by the Wilkes expedition (from Bertrand, 1971, as referred to in Parkinson, 1990) when compared with those of the present show virtually no change in the averaged sea-ice extent, although there are reductions at some locations yet increases at other locations. However, all model simulations show sea-ice reduction at the Wilkes expedition locations but with a smaller magnitude than at Cook's and Bellingshausen's observed locations. Combining the observations recorded by Cook, Bellingshausen and Wilkes, the average sea-ice extent is about $0.71^{\circ}$ less than at present, which is more than the simulated change from $\mathrm{CM}\left(0.44^{\circ}\right)$ but less than the simulated changes from FGISST $\left(1.31^{\circ}\right)$ and FCM $\left(0.91^{\circ}\right)$.

The historical expeditions mainly covered the summer season, December-February. The greatest reduction of seaice extent relative to the present occurs in December, and the smallest in January (Table 3). This agrees with the forcingmodel simulations, but CM shows the greatest change in February. Bearing in mind the uncertainty of the historical observations of sea-ice extent, FCM produces the simulation of changes closest to the observed of the three experiments 
Table 4. Ratio of mean sea-ice-extent change to temperature change (in the Southern Ocean sector $25-65^{\circ} \mathrm{S}$ ) from both observations and model simulations. Units are ${ }^{\circ}$ lat. $K^{-1}$

\begin{tabular}{|c|c|c|c|}
\hline$O B S$ & $C M$ & $F C M$ & FGISST \\
\hline-1.20 & -0.83 & -1.72 & -2.22 \\
\hline
\end{tabular}

conducted. The ratio of mean sea-ice-extent change to temperature change in the Southern Ocean sector $\left(25-65^{\circ} \mathrm{S}\right)$ is given in Table 4 . Observations indicate that a $1^{\circ} \mathrm{C}$ warming corresponds to approximately a $1.20^{\circ}$ retreat in sea ice. This retreat is larger than that simulated by the CSIRO coupled model $\left(0.83^{\circ}\right)$ but smaller than that simulated in the SST forced experiments $\left(1.72^{\circ}\right.$ for FGM and $2.22^{\circ}$ for FGISST).

\subsection{Predicted temperature and sea-ice changes into the next century}

Using the IS92a greenhouse-gases-emission scenario (Houghton and others, 1996), the CSIRO coupled model simulates a

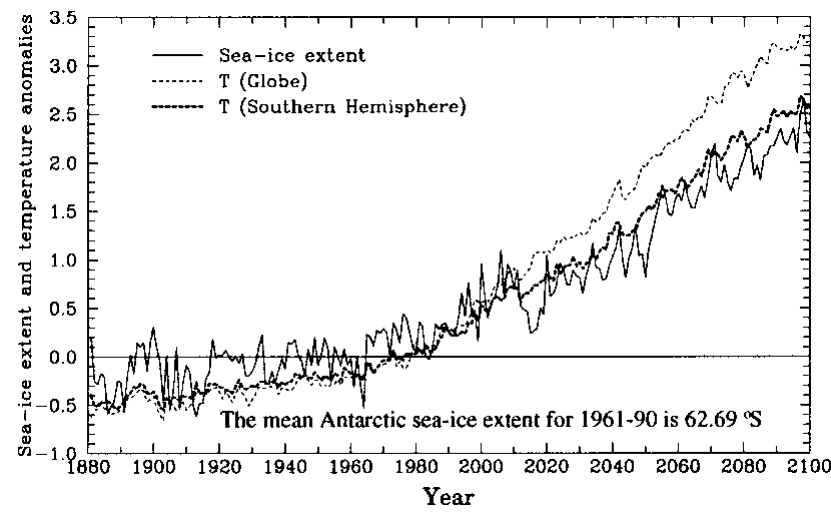

Fig. 2. Coupled-model simulation of the annual mean Antarctic sea-ice extent and surface temperature for both the globe and Southern Hemisphere, 1881-2100. The values are expressed as differences relative to the 30 year average values, 1961-90. The units for sea-ice extent are ${ }^{\circ}$ lat. (positive value means sea-ice edge moves to a higher latitude, indicating a reduction in sea-ice extent). The units of temperature are ${ }^{\circ} \mathrm{C}$.

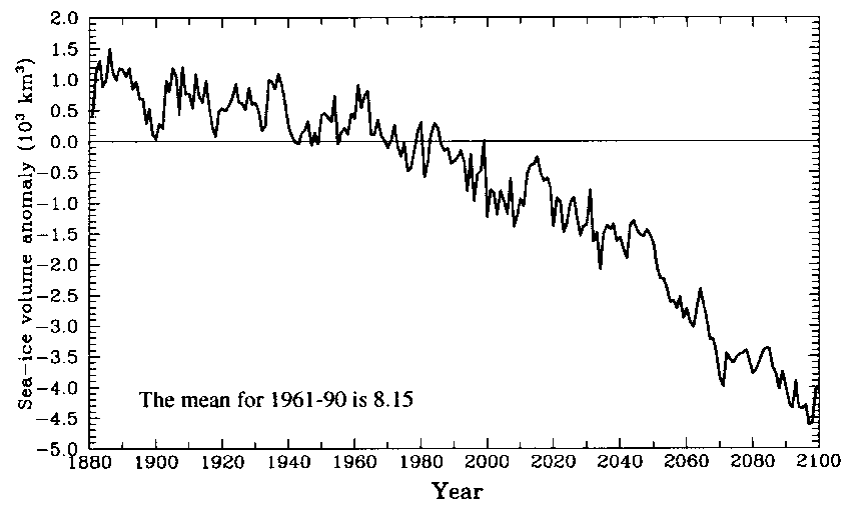

Fig. 3. Coupled-model simulation of the Southern Hemisphere annual mean sea-ice volume, 1881-2100. The values are expressed as differences relative to the 30 year average values 1961-90. global warming of $2.8^{\circ} \mathrm{C}$ and a Southern Hemisphere warming of $2.2^{\circ} \mathrm{C}$ by the end of the next century (Figs 2 and 3; Table 5). This simulation also indicates a reduction in the annual mean Antarctic sea-ice extent of $1.94^{\circ}$, and a reduction in Antarctic sea-ice volume of $>45 \%$ from the present.

Table 5. Coupled-model simulated averages of annual mean surface temperature changes for the globe $(G)$, the Southern Hemisphere ( $\mathrm{SH}$ ), the region 25-65 $\mathrm{S}$ (SOC) and the Antarctic (60 ${ }^{\circ}$ S poleward), 1980-94 to 2080-94. Also given are the annual mean sea-ice-volume and sea-ice-extent changes for the same period

\begin{tabular}{ccccccc}
\hline & \multicolumn{3}{c}{ Temperature change } & \multicolumn{3}{c}{$\begin{array}{c}\text { Sea-ice-volume } \\
\text { change }\end{array}$} \\
$\begin{array}{ccccccc}G & \text { SH } & \text { SOC } & \text { Antartic } & & \text { Sea-extent } \\
\text { change }\end{array}$ \\
${ }^{\circ} \mathrm{C}$ & ${ }^{\circ} \mathrm{C}$ & ${ }^{\circ} \mathrm{C}$ & ${ }^{\circ} \mathrm{C}$ & $\times 10^{3} \mathrm{~km}^{3}$ & $\%$ & ${ }^{\circ}$ lat. \\
\hline 2.86 & 2.22 & 1.93 & 3.07 & -3.63 & -45.7 & 1.94 \\
\hline
\end{tabular}

\section{DISGUSSION AND GONGLUSIONS}

A combination of modelling techniques is used in combination with the limited available observational data to examine the Southern Hemisphere warming and the changes in Antarctic sea ice over the past century. The CSIRO coupled model gives an increase in the Southern Hemisphere mean surface temperature, due to increasing greenhouse gases, from last century to the present, of about $0.6^{\circ} \mathrm{C}$, which is comparable to the observed changes. The modelled temperature changes are less over the Southern Ocean (north of the sea ice) and more over the Antarctic continent and sea-ice regions, which is also in agreement with observations (Jacka and Budd, 1998). The CSIRO coupled-model simulation gives reductions in the mean Antarctic sea-ice extent of about $0.44^{\circ}$ lat. compared to the observations of about $0.71^{\circ}$ lat. based on the mean historical data recorded by the Cook, Bellingshausen and Wilkes expeditions (Parkinson, 1990) and the most recent satellite $(\mathrm{SSM} / \mathrm{I})$ observations. For the two SST forcing cases using the Melbourne University atmosphere-sea-ice model (FCM and FGISST) the resultant seaice-extent changes give larger reductions in mean extent of about $0.91-1.31^{\circ}$ lat., which exceeds both the results from the CSIRO coupled-model simulation and the observations (Table 3). Assuming the two models reproduce plausible low and high estimates for changes in sea-ice coverage, we conclude that the sea-ice extent over the past century has reduced by about $0.4-1.8^{\circ}$ lat. (Table 6 ). We also conclude that the CSIRO coupled model is unlikely to overestimate the changes in sea-ice extent from last century to the present.

Finally, the CSIRO coupled model simulates a global warming of $2.8^{\circ} \mathrm{C}$ and a Southern Hemisphere warming of $2.2^{\circ} \mathrm{C}$ by the end of the next century. This simulation also indicates a reduction in mean sea-ice extent of $1.94^{\circ}$, and a reduction in Antarctic sea-ice volume of $>45 \%$ from the present. With greater sensitivity in the decrease of Antarctic sea-ice extent obtained with the Melbourne University atmosphere- ${ }^{-}$sea-ice model, the decrease of Antarctic seaice extent and volume by that time, for the same temperature change, might be expected to be even larger along with 
Table 6. The change in simulated monthly and annual mean sea-ice extent. The simulated changes refer to the period $1881-1910$ to 1980-94 and all longitudes. Units are ${ }^{\circ}$ lat.

\begin{tabular}{|c|c|c|c|c|c|c|c|c|c|c|c|c|c|}
\hline Exp. & Jan. & Feb. & Mar. & Apr. & May & fun. & ful. & Aug. & Sep. & Oct. & Nov. & $D e c$. & Ann. \\
\hline CM & 0.51 & 0.71 & 0.46 & 0.36 & 0.21 & 0.37 & 0.28 & 0.39 & 0.44 & 0.46 & 0.45 & 0.42 & 0.42 \\
\hline FGISST & 1.39 & 1.47 & 1.57 & 1.62 & 1.33 & 2.33 & 2.47 & 2.07 & 2.64 & 2.31 & 1.61 & 1.69 & 1.88 \\
\hline
\end{tabular}

consequential similar larger reductions in salt flux and Antarctic Bottom Water production. Since the mean temperature changes from greenhouse-gas forcing for the CSIRO coupled model are similar to those obtained from other coupled-model simulations (Houghton and others, 1996) we conclude that the future sea-ice changes simulated by the CSIRO coupled model are not expected to be overestimates of those likely to occur.

\section{ACKNOWLEDGEMENTS}

We thank members of the Climate Modelling Program at CSIRO Atmospheric Research for developing the CSIRO fully coupled model. In particular, A. C. Hirst and S. P. O'Farrell made the CSIRO fully coupled model and data available to us. We would also like to thank I. Simmonds and an anonymous referee for valuable comments which helped to improve the paper.

\section{REFERENCES}

Baker, D. J. 1986. The Arctic's role in climate. Oceanus, 29(1), 41-46.

Bellingshausen, T. 1831. The voyage of Captain Bellingshausen to the Antarctic seas 1819-1821. London, Hakluyt Society. (1945 translation.)

Bertrand, K. J. 1971. Americans in Antarctica 1775-1948. New York, American Geographical Society.

Budd, W. F. 1991. Antarctica and global change. Climatic Change, 18(2-3), 271-299.

Connolley, W. M. and S. P. O'Farrell. 1998. Comparison of warming trends over the last century around Antarctica from three coupled models. Ann. Glaciol., 27, 565-570.

Cook, J. 1777. A voyage towards the South Pole, and round the world. Performed in His Majesty's ships the "Resolution" and "Adventure" in the years 1772, 1773, 1774, and 1775. London, W. Strahan and T. Cadell.

De la Mare, W.K. 1997. Abrupt mid-twentieth century decline in Antarctic sea-ice extent from whaling records. Nature, 389(6646), 57-61.

Flato, G. M. and W. D. Hibler, III. 1992. Modeling pack ice as a cavitating fluid. 7. Phys. Oceanogr., 22(6), 626-651.

Gent, P. R. and J. C. McWilliams. 1990. Isopynal mixing in ocean circulation models. 7. Phys. Oceanogr., 20 (1), 150-155.

Gordon, H. B. and S. P. O'Farrell. 1997. Transient climate change in the CSIRO coupled model with dynamic sea-ice. Mon. Weather Rev., 125(5), 875-907.

Hanna, E. 1996. The role of Antarctic sea ice in global climate change. Prog. Phys. Geogr., 20(4), 371-401.

Herdman, H. F. P. 1948. The Antarctic pack-ice. F. Glaciol., 1(4), 156-166/172-173.

Hirst, A. C. 1999. The Southern Ocean response to global warming in the CSIRO coupled ocean-atmosphere model. Environmental Modeling and
Software, 14, 227-241.

Hirst, A. C. and T. J. McDougall. 1996. Deep-water properties and surface buoyancy flux as simulated by a z-coordinate model including eddyinduced advection. 7. Phys. Oceanogr., 26(7), 1320-1343.

Hirst, A. C., H. B. Gordon and S. P. O'Farrell. 1996. Global warming in a coupled climate model including oceanic eddy-induced advection. Geophys. Res. Lett., 23 (23), 3361-3364.

Houghton, J.T., L. G. M. Filho, B. A. Callander, N. Harris, A. Kattenberg and K. Maskell, eds. 1996. Climate change 1995: the science of climate change. Cambridge, etc., Cambridge University Press.

Jacka, T. H. and W. F. Budd. 1998. Detection of temperature and sea-ice- extent changes in the Antarctic and Southern Ocean, 1949-96. Ann. Glaciol., 27, 553-559.

Jones, P. D. 1994. Hemispheric surface temperature variations: a reanalysis and an update to 1993. F. Climate, 7(11), 1794-1802.

Kelly, P. M. and P. D. Jones. 1996. Removal of the El Niño-Southern Oscillation signal from the gridded surface air temperature data set. F. Geophys. Res., 101(D14), 19,013-19,022.

McGregor, J. L., H. B. Gordon, I. G. Watterson, M. R. Dix and L. D. Rotstayn. 1993. The CSIRO 9-level atmospheric general circulation model. Melbourne, Australia, CSIRO. Division of Atmospheric Research. (Technical Paper 26.)

Meinardus, W. 1938. Klimakunde der Antarktis. In Köppen, W. and R. Geiger, eds. Handbuch der Klimatologie. Vol. IV $(U)$. Berlin, Verlag von Gebrüder Borntraeger.

O'Farrell, S. P. 1998. Sensitivity study of a dynamic sea ice model: the effect of the external stresses and land boundary conditions on ice thickness distribution. 7. Geophys. Res., 103 (C8), 15,751-15,782.

Parker, D. E., M. Jackson and E. B. Horton. 1995a. The GISST 2.2 sea surface temperature and sea ice climatology. Bracknell, Meteorological Office. Hadley Centre for Climate Prediction and Research. (Climate Research Technical Note CRTN 63.)

Parker, D. E., C. K. Folland and M. Jackson. 1995b. Marine surface temperature: observed variations and data requirements. Climatic Change, $31(2-4), 559-600$.

Parkinson, C. L. 1990. Search for the Little Ice Age in Southern Ocean seaice records. Ann. Glaciol., 14, 221-225.

Renkin, A. 1997. Historical and modern records of Antarctic sea ice extent. (Honours thesis, University of Tasmania. Institute of Antarctic and Southern Ocean Studies.)

Reynolds, R.W. 1988. A real-time global sea surface temperature analysis. 7. Climate, $\mathbf{1}(1), 75-86$.

Semtner, A. J., Jr. 1976. A model for the thermodynamic growth of sea ice in numerical investigations of climate. 7. Phys. Oceanogr., 6 (5), 379-389.

Simmonds, I. 1985. Analysis of the "spinup" of a general circulation model. 7. Geophys. Res., 90 (D3), 5637-5660.

Worby, A. P. and X. Wu. 1998. East Antarctic sea ice: observations and modelling. Ann. Glaciol., 27, 427-432.

Wu, X., I. Simmonds and W. F. Budd. 1997. Modeling of Antarctic sea ice in a general circulation model. f. Climate, 10(4), 593-609.

Wu, X., W. F. Budd, V. I. Lytle and R. A. Massom. 1999. The effect of snow on Antarctic sea ice simulation in a coupled atmosphere-sea ice model. Climate Dyn, $15(2), 127-143$. 